\title{
openheart Cardiac remodelling and haemodynamic characteristics in primary mitral valve regurgitation
}

\author{
Rine Bakkestrøm, ${ }^{1}$ Ann Banke, ${ }^{1}$ Redi Pecini, ${ }^{1}$ Akhmadjon Irmukhamedov, ${ }^{1}$ \\ Søren Kristian Nielsen, ${ }^{1}$ Mads J Andersen, ${ }^{1,2}$ Barry A Borlaug, ${ }^{1,3}$ Jacob Eifer Moller ${ }^{1}$
}

To cite: Bakkestrøm R, Banke A, Pecini R, et al. Cardiac remodelling and haemodynamic characteristics in primary mitral valve regurgitation. Open Heart 2018;5:e000919. doi:10.1136/ openhrt-2018-000919

Received 14 August 2018 Revised 2 October 2018 Accepted 12 November 2018

Check for updates

(c) Author(s) (or their employer(s)) 2018. Re-use permitted under CC BY-NC. No commercial re-use. See rights and permissions. Published by BMJ.

'Department of Cardiology, Odense University Hospital, Odense Denmark and Odense Patient data Explorative Network OPEN, Odense, Denmark ${ }^{2}$ Department of Cardiology, Aarhus University Hospital, Aarhus, Denmark

${ }^{3}$ Department of Cardiovascular Medicine, Mayo Clinic, Rochester, Minnesota, USA

Correspondence to Dr Jacob Eifer Moller; jacob. moeller1@rsyd.dk

\section{ABSTRACT}

Objective To assess the association between cardiac morphology and function assessed with cardiac MRI (CMRI) and haemodynamics at rest and during exercise in patients with primary mitral regurgitation (MR).

Methods In an observational study, subjects with significant primary MR $(\mathrm{N}=46)$ with effective regurgitant orifice $\geq 0.30 \mathrm{~cm}^{2}$ and left ventricular (LV) ejection fraction $>60 \%$ were examined with right heart catheterisation during rest and exercise and CMRI at rest. End-diastolic pressure volume relationship (EDPVR) was assessed using a single beat method using pulmonary capillary wedge pressure (PCWP) and end-diastolic volume. Patients were divided according to normal PCWP at rest $(>12 \mathrm{~mm}$ $\mathrm{Hg}$ ) and with exercise (> $28 \mathrm{~mm} \mathrm{Hg}$ ). Results: Resting regurgitant volume correlated positively with resting PCWP, $(r=0.42, p=0.002)$. However, with exercise no association between PCWP and regurgitant volume was seen $(r=0.09, p=0.55)$. At rest left atrial $(L A)$ maximal, minimal and volume index at atrial contraction correlated positively with PCWP $(r=0.60 ; r=0.55 ; r=0.58$, all $p<$ 0.001 ); in contrast none of these correlated with exercise PCWP (all $p>0.2$ ). EDPVR in patients with high PCWP at rest was shifted towards higher volumes for the same pressures. The opposite was seen for patients with high PCWP during exercise where estimated volumes were smaller for the same pressure than patients with normal exercise PCWP.

Conclusion In patients with significant MR the degree of regurgitation and LA dilatation is associated with resting PCWP. However, with exercise this association disappears. Estimation of EDPVR suggests lower LV compliance in patients where PCWP is increased with exercise. Clinical trial registration URL: https://clinicaltrials. gov/ct2/show/NCT02961647?term=HEMI\&rank=1. ID: NCT02961647

\section{INTRODUCTION}

Primary mitral valve regurgitation due to degenerative valve disease is the second most common form of valvular heart disease in the Western world. ${ }^{1}$ The consequence of mitral regurgitation (MR) is left ventricular (LV) and left atrial (LA) volume overload with dilatation of cardiac chambers and eventually dysfunction of affected chambers. LV and LA

\section{Key questions}

What is already known about this subject?

- Cardiac MRI (CMRI) can assess and quantify severity of mitral regurgitation (MR) and left ventricular (LV) function and size with high accuracy.

- Although CMRI is attractive the vast burden of evidence in MR is based on echocardiographic assessment where neither regurgitant volume nor LV size and function may be interchangeable between imaging modalities.

What does this study add?

- The present study in significant primary MR reveals that the degree of left atrial (LA) dilatation is associated with resting pulmonary capillary wedge pressure (PCWP), and pulmonary artery pressure at rest. However, with exercise these associations disappear, and exercise PCWP is not associated with severity of dilatation.

- Estimation of end-diastolic pressure volume relationship suggests that filling pressures with exercise are also determined by intrinsic LV diastolic properties in primary MR, whereas resting haemodynamics are primarily determined by severity of MR.

How might this impact on clinical practice?

- The study provides insights and understanding of LA dilatation and function assessed with CMRI in primary MR as well as understanding of determinants of elevated filling pressure with exercise.

dilatation is a hallmark of significant MR and carries important prognostic information..$^{2-4}$ The changes in LA and LV function are key elements to understand the haemodynamic consequence of disease and are pivotal in guidance of therapy.

Cardiac MRI (CMRI) can assess and quantify MR severity using phase velocity encoded CMRI based on indirect measures of differential stroke volumes (SVs) ${ }^{56}$ Further, cine-CMR can quantify changes in LV function and size with high accuracy and thus seems attractive to guide decision making for mitral valve interventions. ${ }^{7-9}$ Recent data have suggested that compared with using echocardiography, 
assessment of severity of MR using CMRI provides better accuracy in identifying patients who will develop the need for surgery and also improves the outcome after surgery ${ }^{7-9}$ Although CMRI is attractive, the vast burden of evidence in MR is based on echocardiographic assessment where neither regurgitant volume nor LV size and function may be interchangeable between imaging modalities. ${ }^{7-9}$

Thus, in the present study we sought to determine the association between cardiac morphology and function assessed with CMRI and central haemodynamics especially in terms of increased filling pressure assessed with right heart catheterisation at rest and during exercise in patients with significant primary MR.

\section{METHODS}

This was a prospective single-centre study evaluating consecutive stable patients with significant MR. ${ }^{10}$ Outpatients $\geq 18$ years of age with either asymptomatic or symptomatic significant organic MR (effective regurgitant orifice (ERO) $\geq 0.3 \mathrm{~cm}^{2}$ ) were invited to participate. Patients with LV ejection fraction (LVEF) $<60 \%$ on transthoracic echocardiography, concomitant moderate-to-severe aortic stenosis or regurgitation, persistent atrial fibrillation, significant cardiac shunt, estimated glomerular filtration rate $<40 \mathrm{~mL} / \mathrm{min}$, known history of cardiomyopathy, or obstructive or restrictive pulmonary disease, were not eligible. Patients unable to perform exercise testing or with claustrophobia were excluded. A transesophageal echocardiogram was performed to determine valve morphology and characteristics of the prolapse. Patients with severe MR (ERO $\left.>0.4 \mathrm{~cm}^{2}\right)$ irrespective of symptoms were discussed at the heart team conference for possible mitral valve repair. The heart team was blinded to the result of CMRI and in most cases right heart catheterisation was done after heart team discussion.

The study was conducted according to the Declaration of Helsinki and registered at the Danish Data Protection Agency, and at ClinicalTrials.gov with identifier NCT01974557. All participants provided written consent.

\section{Cardiac MRI}

CMRI was performed on a Philips Ingenia 1.5T scanner with an Omega HP gradient system (Philips Electronics, Koninklijke, Netherlands). Eighteen-24 sequential short-axis slices enclosing the entire heart were obtained during multiple end-expiratory breath hold sequences acquiring slices of $8 \mathrm{~mm}$ thickness. A 32-channel Stream Torso coil was used during image acquisition. Delayed enhancement imaging was performed 10-15 min after administration of $0.1 \mathrm{mmol} / \mathrm{kg}$ gadoterate meglumine (Dotarem, Guerbet, Aulnay-Bois, France). Optimal inversion time (TI), in order to null the myocardium, was determined using a Look-Locker sequence with multiple images with varying TI. Images were analysed blinded for clinical and echocardiographic data by an experienced examiner on a dedicated workstation with a Philips Workspace software package (V.2.6.3.5 2013).

Atrial and ventricular chamber volumes and LV mass were acquired from a cine sequence with continuous short axis slices covering the atria and ventricles down to apex. ${ }^{11}$ With maximal volumes, endocardial and epicardial borders were manually traced as previously described. ${ }^{12}$ Papillary muscles were considered as part of the LV cavity and excluded from LV mass, and the left atrial appendage volume was included in the LA volume. $\mathrm{LV}$ and right ventricular (RV) volumes were used to calculate LVEF and RV ejection fraction. LA maximal, LA volume at preatrial contraction and LA minimal volume were measured, and LA fractional change (maximal volume minus minimal volume) and LA active emptying fraction (LA preatrial contraction volume minus minimal volume) were calculated.

Phase velocity flow mapping of flow volumes in the aorta obtained at the sinotubular junction were used to assess forward flow through the aortic valve (forward LV $\mathrm{SV})$. The spatial resolution was $2.5 \times 2.5 \mathrm{~mm}$ using an 8 $\mathrm{mm}$ slice thickness. The temporal resolution used was 25-55 ms. The initial encoding velocity was set at 200 $\mathrm{cm} / \mathrm{s}$ with increments of $50 \mathrm{~ms}$, if aliasing was present. The regurgitated volume through the mitral valve was calculated as (LV end-diastolic volume - LV end-systolic volume) minus aortic SV. ${ }^{5}$ MR volume was categorised per American Heart Association/American College of Cardiology guidelines as severe when exceeding $60 \mathrm{~mL} .{ }^{11}$

\section{Right heart catheterisation}

Right heart catheterisation was performed using a standard 7.5 F triple lumen Swan-Ganz catheter (Edwards Lifesciences, Irvine, California, USA), introduced using the Seldinger technique into the right internal jugular vein. Subjects were examined on chronic medications in the supine position at rest and in the semisupine position $\left(30^{\circ}\right)$ during exercise. Workload was increased by 25 Watts every third minute. Pulmonary capillary wedge pressure (PCWP), mean right atrial pressure, systolic pulmonary artery pressure (PAP), diastolic PAP, mean $\mathrm{PAP}$ and cardiac output $(\mathrm{CO})$ were measured at rest and peak exercise. PCWP (mid A-wave pressure) at rest was measured at end-expiration; during exercise PCWP was averaged over $10 \mathrm{~s}$ avoiding prominent $\mathrm{V}$-waves. If large V-waves were present this was also measured (defined as V-wave $\geq 7 \mathrm{~mm} \mathrm{Hg}$ higher than mean PCWP). ${ }^{13} \mathrm{CO}$ was measured using thermodilution as the average of three measurements with $<10 \%$ difference. If measurements differed $>10 \%$ they were repeated and subsequently excluded if still differing. $\mathrm{CO}$ was indexed to body surface area (Dubois formula) as Cardiac Index. At rest and at peak exercise a central venous blood sample was drawn from the pulmonary artery and analysed for lactate concentration, mixed venous oxygen saturation and $\mathrm{pH}$. At rest PCWP $\leq 12 \mathrm{~mm} \mathrm{Hg}$ and mean $\mathrm{PAP}<25$ $\mathrm{mm} \mathrm{Hg}$ were considered normal values, and PCWP $\leq 28$ $\mathrm{mm} \mathrm{Hg}$ at peak exercise was considered normal. ${ }^{14}$ 
Estimation of end-diastolic pressure volume relationship

End-diastolic pressure volume relationship (EDPVR) can be described by the non-linear expression:

LV end-diastolic pressure (LVEDP) $=\alpha \times($ LVEDV $) \beta^{15}$

Using this equation EDPVR was estimated for all patients using a single-beat estimation technique which has been described in detail previously. ${ }^{15} 16$ The resting PCWP measured at mid A-wave, avoiding $\mathrm{V}$ waves was used as a surrogate for LVEDP, and LVEDV was determined from CMRI. Based on these measurements $\alpha$ and $\beta$ were estimated for each individual patient. Then, in each subject LVEDV for predefined values of LVEDP: 5 $\mathrm{mm} \mathrm{Hg}, 10 \mathrm{~mm} \mathrm{Hg}, 15 \mathrm{~mm} \mathrm{Hg}, 20 \mathrm{~mm} \mathrm{Hg}, 25 \mathrm{~mm} \mathrm{Hg}$ and $30 \mathrm{~mm} \mathrm{Hg}$ were calculated.

Estimation of plasma volume

Plasma volume was estimated as follows: (1-haematocrit $) \times(\mathrm{a}+(\mathrm{b} \times$ weight in $\mathrm{kg}))$, where $\mathrm{a}=1530$ for men and 864 for women and $b=41$ for men and 47.9 for women. ${ }^{1718}$

\section{Statistical analysis}

Data are presented as mean $\pm \mathrm{SD}$ or median (IQR) unless otherwise indicated. Between-group differences were tested using analysis of variance, $\chi^{2}$ test, or non-parametrical rank-sum test for non-Gaussian distributed variables. Simple bivariate associations were assessed using the Pearson correlation coefficient. Multiple regression analysis was used to evaluate associations between PCWP at rest and with exercise and regurgitant volume, $\mathrm{LV}$, and LA size and function, adjusted for age and gender and type of prolapse. Model assumptions were tested (linear relationship, normality, collinearity and homoscedasticity) and found valid. Further, no interactions were identified. SPSS (IBM Statistics, V.21.0) software was used for statistical analysis. A value of $\mathrm{p}<0.05$ was considered statistically significant.

\section{RESULTS}

Among 125 patients with significant MR, 68 declined participation and 57 were enrolled (table 1) where CMRI (table 2) was available in 46 patients. Twenty-five patients (54\%) were asymptomatic and $21(46 \%)$ were symptomatic (NYHA class II-III). CMRI was done median 0 days (IQR -2 days to 6 days) after right heart catheterisation. After heart team discussion 21 patients were referred for surgery (18 class I indication, 2 with class 2A indication (paroxysmal atrial fibrillation) and 1 class 2B indication).

\section{Regurgitant volume}

Invasive haemodynamics at rest and at peak exercise according to regurgitant volume are summarised in table 3. Resting PCWP was increased $>12 \mathrm{~mm} \mathrm{Hg}$ in 8 patients $(33 \%)$ with regurgitant volume $<60 \mathrm{~mL}$ compared with $17(77 \%)$ with regurgitant volume $\geq 60$ $\mathrm{mL}(\mathrm{p}=0.01)$, and regurgitant volume correlated positively with PCWP (figure 1). However, with exercise no difference in patients with increased exercise PCWP $(\geq 28 \mathrm{~mm} \mathrm{Hg}$ ) according to regurgitant volume was seen
Table 1 Clinical characteristics

\begin{tabular}{|c|c|}
\hline & All patients $(n=46)$ \\
\hline Age, years & $65 \pm 9$ \\
\hline Gender, male (\%) & $36(78)$ \\
\hline Body surface area, $\mathrm{m}^{2}$ & $1.96 \pm 0.18$ \\
\hline Current smoker (\%) & $7(15)$ \\
\hline Hypertension (\%) & $9(20)$ \\
\hline Diabetes mellitus (\%) & $0(0)$ \\
\hline IHD (\%) & $5(11)$ \\
\hline Stroke (\%) & $1(4)$ \\
\hline Intermittent atrial fibrillation (\%) & $6(13 \%)$ \\
\hline NYHA class 2 or 3 & $18(39 \%)$ \\
\hline FEV1, L/min & $3.2 \pm 0.78$ \\
\hline $\mathrm{eGFR}, \mathrm{mL} / \mathrm{min}$ & $80 \pm 12$ \\
\hline Systolic blood pressure & $134 \pm 12$ \\
\hline Haemoglobin $(\mathrm{mmol} / \mathrm{l})$ & $8.0 \pm 0.8$ \\
\hline Haematocrit & $0.38 \pm 0.03$ \\
\hline \multicolumn{2}{|l|}{ Medication } \\
\hline ACEi/ARB & $10(24 \%)$ \\
\hline$\beta$ blocker & $5(11 \%)$ \\
\hline Calcium channel blocker & $6(13 \%)$ \\
\hline Diuretic & $10(24 \%)$ \\
\hline Anticoagulation & $5(11 \%)$ \\
\hline \multicolumn{2}{|l|}{ Echocardiographic characteristics } \\
\hline $\operatorname{LVEF}(\%)$ & $70 \pm 7$ \\
\hline $\operatorname{ERO}\left(\mathrm{cm}^{2}\right)$ & $0.50 \pm 0.25$ \\
\hline Regurgitant volume (ml) & $84 \pm 46$ \\
\hline Bileaflet prolapse (\%) & $14(30 \%)$ \\
\hline Posterior prolapse (\%) & $41(89 \%)$ \\
\hline Anterior prolapse (\%) & $17(37 \%)$ \\
\hline Flail leaflet (\%) & $11(24 \%)$ \\
\hline Ruptured chord (\%) & $22(52 \%)$ \\
\hline
\end{tabular}

Data are number and (\%) or mean \pm SD.

ACEi/ARB, ACE inhibitor / angiotensin 2 receptor blocker; ERO, effective regurgitant orifice; FEV1, forced expiratory volume (1 sec); IHD, ischaemic heart disease; LVEF, left ventricular ejection fraction; NYHA, New York Heart Association functional class; eGFR, estimated glomerular filtration rate.

(12/24 patients vs $12 / 22$ patients, $\mathrm{p}=0.65)$, and $\mathrm{PCWP}$ at peak exercise did not correlate with regurgitant volume at rest. Also resting PAP was increased with increased regurgitant volume. Although, $\mathrm{CO}$ and RV stroke work were the same, LV stroke work was increased with increased regurgitant volume, table 3 .

\section{LA size and function}

In general the LA was severely dilated in patients with increased and normal PCWP. Patients with increased resting PCWP (>12 $\mathrm{mm} \mathrm{Hg}$ ) had larger LA maximal $\left(100 \pm 24 \mathrm{~mL} / \mathrm{m}^{2}\right.$ vs $\left.83 \pm 17 \mathrm{~mL} / \mathrm{m}^{2}, \mathrm{p}=0.005\right)$, minimal 
Table 2 Cardiac MRI measurements and plasma volume according to regurgitant volume.

\begin{tabular}{|c|c|c|c|}
\hline & $\begin{array}{l}\text { Regurgitant } \\
\text { volume <60 } \\
\mathrm{mL}(\mathrm{N}=24)\end{array}$ & $\begin{array}{l}\text { Regurgitant } \\
\text { volume } \geq 60 \\
\mathrm{~mL}(\mathrm{~N}=22)\end{array}$ & $P$ value \\
\hline Plasma volume, mL & $2924 \pm 354$ & $3050 \pm 342$ & 0.22 \\
\hline Regurgitant volume, $\mathrm{mL}$ & $38 \pm 13$ & $79 \pm 18$ & $<0.001$ \\
\hline Regurgitant fraction, \% & $31 \pm 10$ & $48 \pm 8$ & $<0.001$ \\
\hline $\begin{array}{l}\text { LV End-Diastolic Volume } \\
\text { Index, } \mathrm{mL} / \mathrm{m}^{2}\end{array}$ & $101 \pm 14$ & $130 \pm 22$ & $<0.001$ \\
\hline $\begin{array}{l}\text { LV End-Systolic Volume } \\
\text { Index, } \mathrm{mL} / \mathrm{m}^{2}\end{array}$ & $39 \pm 9$ & $48 \pm 14$ & 0.009 \\
\hline LV ejection fraction, \% & $63 \pm 8$ & $64 \pm 6$ & 0.71 \\
\hline $\begin{array}{l}\text { Total LV Stroke Volume } \\
\text { Index, } \mathrm{mL} / \mathrm{m}^{2}\end{array}$ & $63 \pm 8$ & $83 \pm 12$ & $<0.001$ \\
\hline $\begin{array}{l}\text { Indexed aorta flow*, mL/ } \\
\mathrm{m}^{2}\end{array}$ & $41 \pm 8$ & $39 \pm 8$ & 0.75 \\
\hline LV wall mass index, $\mathrm{g} / \mathrm{m}^{2}$ & $57 \pm 12$ & $70 \pm 18$ & 0.006 \\
\hline $\begin{array}{l}\text { LV mass/LV end-diastolic } \\
\text { volume, } g / \mathrm{mL}\end{array}$ & $0.56 \pm 0.08$ & $0.53 \pm 0.12$ & 0.42 \\
\hline $\begin{array}{l}\text { LA Max Volume Index, } \\
\mathrm{mL} / \mathrm{m}^{2}\end{array}$ & $80 \pm 16$ & $105 \pm 21$ & $<0.001$ \\
\hline $\begin{array}{l}\text { LA pre A volume index, } \\
\mathrm{mL} / \mathrm{m}^{2}\end{array}$ & $59 \pm 13$ & $76 \pm 15$ & $<0.001$ \\
\hline $\begin{array}{l}\text { LA Minimal Volume Index, } \\
\mathrm{mL} / \mathrm{m}^{2}\end{array}$ & $44 \pm 14$ & $58 \pm 18$ & 0.008 \\
\hline LA fractional change, \% & $46 \pm 9$ & $46 \pm 8$ & 0.76 \\
\hline $\begin{array}{l}\text { LA active systolic } \\
\text { emptying fraction, \% }\end{array}$ & $27 \pm 9$ & $26 \pm 10$ & 0.63 \\
\hline $\begin{array}{l}\text { RV End-Diastolic Volume } \\
\text { Index, } \mathrm{ml} / \mathrm{m}^{2}\end{array}$ & $68 \pm 14$ & $70 \pm 15$ & 0.60 \\
\hline $\begin{array}{l}\text { RV End-Systolic Volume } \\
\text { Index, } \mathrm{ml} / \mathrm{m}^{2}\end{array}$ & $27 \pm 7$ & $32 \pm 11$ & 0.09 \\
\hline RV ejection fraction, \% & $60 \pm 7$ & $55 \pm 9$ & 0.02 \\
\hline $\begin{array}{l}\text { RV Stroke Volume Index, } \\
\mathrm{ml} / \mathrm{m}^{2}\end{array}$ & $41 \pm 9$ & $38 \pm 9$ & 0.35 \\
\hline
\end{tabular}

Data are mean \pm SD unless otherwise indicated.

*(Aortic forward flow-aortic backward flow)/body surface area.

LA, left atrial; LV, left ventricular; RV, right ventricular.

$\left(56 \pm 17 \mathrm{~mL} / \mathrm{m}^{2}\right.$ vs $\left.44 \pm 15 \mathrm{~mL} / \mathrm{m}^{2}, \mathrm{p}=0.01\right)$ and LA preatrial contraction volume index $\left(73 \pm 16 \mathrm{~mL} / \mathrm{m}^{2}\right.$ vs $61 \pm 13$ $\left.\mathrm{mL} / \mathrm{m}^{2}, \mathrm{p}=0.007\right)$. However, no difference in LA function in terms of fractional change $(0.44 \pm 0.06$ vs $0.48 \pm 0.10$, $\mathrm{p}=0.22)$ or LA active emptying fraction $(0.24 \pm 0.10$ vs $0.29 \pm 0.10, p=0.07)$ was seen between groups. LA volumes or function were not different in patients with or without large V-wave.

Further, no differences in LA volumes or function were found between patients with increased exercise PCWP $(>28 \mathrm{~mm} \mathrm{Hg}$ ) or normal PCWP with exercise.

At rest LA maximal, minimal and pre A volume index correlated positively with PCWP $(\mathrm{r}=0.60, \mathrm{p}<0.001$ (figure 2) $\mathrm{r}=0.55, \mathrm{p}<0.001 ; \mathrm{r}=0.58, \mathrm{p}<0.001$, respectively) and V-wave $(\mathrm{r}=0.61, \mathrm{p}<0.001 ; \mathrm{r}=0.55, \mathrm{p}<0.001 ; \mathrm{r}=0.55$, $\mathrm{p}<0.001$, respectively). LA active emptying fraction was negatively associated with resting PCWP $(\mathrm{r}=-0.38$, $\mathrm{p}=0.009$ ) but not fractional change $\mathrm{r}=-19, \mathrm{p}=0.20)$. The association between LA maximal volume index and resting PCWP remained significant $(\beta=0.41, p=0.005)$ in a linear regression model that also included age, gender, flail leaflet, regurgitant volume and LVEDV Index. In that model also presence of flail leaflet $(\mathrm{p}=0.004)$ and LVEDV Index $(\mathrm{p}=0.01)$ was associated with PCWP.

In contrast neither LA size nor LA function showed any statistically significant associations with peak exercise PCWP (figure 2) or V-wave.

\section{End-diastolic pressure volume relationship}

Estimated EDPVR is shown in figure 3. These curves represent predicted LVEDV for a given physiological LVEDP. Compared with the group with normal PCWP at rest, the curve of the high PCWP group was shifted towards higher volumes for the same pressures, reflecting increased compliance, (figure 3A). This was associated with higher plasma volume in patients with elevated resting PCWP $(3096 \pm 253 \mathrm{~mL}$ vs $2851 \pm 408 \mathrm{~mL}, \mathrm{p}=0.01)$. However the opposite was seen for patients with high PCWP; during exercise these patients had smaller estimated volumes for same pressure and the slope of EDPVR was steeper than patients with low PCWP during exercise, (figure 3B). There was no difference in plasma volume in patients with elevated or normal exercise PCWP $(3017 \pm 315 \mathrm{~mL}$ vs $2950 \pm 400 \mathrm{~mL}, \mathrm{p}=0.54$ ).

Among patients referred for surgery 14 patients (67\%) had increased exercise PCWP ( $>28 \mathrm{mmHg}$ ), opposed to $7(28 \%)$ among patients not referred for surgery, $\mathrm{p}=0.01$.

\section{DISCUSSION}

The present exploratory study in significant primary MR reveals that the degree of LA dilatation is associated with resting PCWP, V-wave and PAP at rest. However, with exercise these associations disappear, and exercise PCWP is not associated with severity of dilatation. Estimation of EDPVR suggests lower compliance for patients with elevated PCWP with exercise, whereas increased PCWP at rest was associated with enhanced LV compliance. Collectively, these findings suggest that filling pressures with exercise are also determined by intrinsic LV diastolic properties in primary MR, whereas resting haemodynamics are primarily determined by severity of MR.

Several methods have been proposed to assess the severity of MR with CMRI. ${ }^{56}$ In the present study the method based on subtracting the aortic forward flow from the LV SV was used. Although this method has been reported to yield higher regurgitant volumes than direct measurements, it has highest reproducibility. ${ }^{5} 619$ In the clinical setting this method has been demonstrated to carry important information both in symptomatic and asymptomatic patients ${ }^{7-9}$ and is the method recommended in the AHA/ACC guidelines for management 
Table 3 Invasive haemodynamic measurements at rest and during exercise according to regurgitated volume on cardiac MRI (CMRI)

\begin{tabular}{|c|c|c|c|c|c|c|}
\hline & \multicolumn{3}{|l|}{ Rest } & \multicolumn{3}{|l|}{ Peak exercise } \\
\hline & $\begin{array}{l}\text { Regurgitant } \\
\text { volume }<60 \mathrm{~mL}\end{array}$ & $\begin{array}{l}\text { Regurgitant } \\
\text { volume vol } \geq 60 \\
\mathrm{~mL}\end{array}$ & $P$ value & $\begin{array}{l}\text { Regurgitant } \\
\text { volume }<60 \mathrm{~mL}\end{array}$ & $\begin{array}{l}\text { Regurgitant } \\
\text { volume } \geq 60 \mathrm{~mL}\end{array}$ & $P$ value \\
\hline Watts at max. exercise & - & - & - & $111 \pm 46$ & $129 \pm 36$ & 0.17 \\
\hline Estimated $\mathrm{VO}_{2}$ (Fick), $\mathrm{ml} / \mathrm{kg}$ & $2.8 \pm 0.8$ & $2.6 \pm 0.6$ & 0.51 & $18.7 \pm 6.7$ & $18.8 \pm 4.3$ & 0.67 \\
\hline Heart rate & $66 \pm 14$ & $67 \pm 10$ & 0.71 & $122 \pm 19$ & $130 \pm 16$ & 0.12 \\
\hline MAP, mm Hg & $89 \pm 9$ & $91 \pm 9$ & 0.57 & $106 \pm 14$ & $112 \pm 18$ & 0.23 \\
\hline Mean RAP, mm Hg & $6 \pm 3$ & $7 \pm 4$ & 0.52 & $11 \pm 6$ & $10 \pm 4$ & 0.97 \\
\hline PAP systolic, mm Hg & $27 \pm 6$ & $32 \pm 9$ & 0.04 & $57 \pm 12$ & $63 \pm 13$ & 0.11 \\
\hline PAP diastolic, $\mathrm{mm} \mathrm{Hg}$ & $12 \pm 3$ & $14 \pm 5$ & 0.11 & $27 \pm 6$ & $30 \pm 6$ & 0.09 \\
\hline PAP mean, $\mathrm{mm} \mathrm{Hg}$ & $18 \pm 4$ & $21 \pm 7$ & 0.04 & $41 \pm 8$ & $45 \pm 8$ & 0.09 \\
\hline PCWP, mm Hg & $11 \pm 3$ & $14 \pm 4$ & 0.002 & $27 \pm 7$ & $28 \pm 7$ & 0.44 \\
\hline $\mathrm{CO}, \mathrm{L} / \mathrm{min}$ & $4.9 \pm 1.2$ & $5.3 \pm 1.2$ & 0.32 & $13.2 \pm 4.0$ & $14.2 \pm 2.9$ & 0.34 \\
\hline $\mathrm{Cl}, \mathrm{l} / \mathrm{min} / \mathrm{m}^{2}$ & $2.6 \pm 0.5$ & $2.6 \pm 0.5$ & 0.85 & $6.8 \pm 1.4$ & $7.1 \pm 1.3$ & 0.41 \\
\hline LV stroke work, $g^{*} m$ & $138 \pm 31$ & $186 \pm 34$ & $<0.001$ & & & \\
\hline RV stroke work, $g^{\star} m$ & $7.4 \pm 3.9$ & $7.2 \pm 5.8$ & 0.89 & & & \\
\hline PAPI & $3.0 \pm 1.4$ & $3.4 \pm 2.2$ & 0.39 & $3.1 \pm 1.4$ & $3.1 \pm 1.1$ & 0.94 \\
\hline $\mathrm{SVO}_{2}$ & $72 \pm 6$ & $75 \pm 5$ & 0.11 & $35 \pm 11$ & $36 \pm 11$ & 0.77 \\
\hline Lactate, $\mathrm{mmol} / \mathrm{L}$ & $0.6 \pm 0.3$ & $0.6 \pm 0.2$ & 0.79 & $4.1 \pm 1.7$ & $5.3 \pm 1.8$ & 0.04 \\
\hline
\end{tabular}

Data are mean \pm SD.

$\mathrm{CI}$, Cardiac Index; CO, cardiac output; LV, left ventricular; MAP, mean arterial pressure; PAP, pulmonary artery pressure; PAPI, Pulmonary Pulsatility Index; PCWP, pulmonary capillary wedge pressure; RAP, right atrial pressure; RV, right ventricular; $\mathrm{SVO}_{2}$, mixed venous oxygen saturation; $\mathrm{VO}_{2}$, maximal oxygen consumption.

of valvular disease, ${ }^{11}$ Haemodynamically, regurgitant volume correlated positively with PCWP, mPAP, V-wave and LV stroke work at rest. This provides a clear link between the severity of MR assessed with CMRI and the haemodynamic consequence of MR.

\section{A Rest}

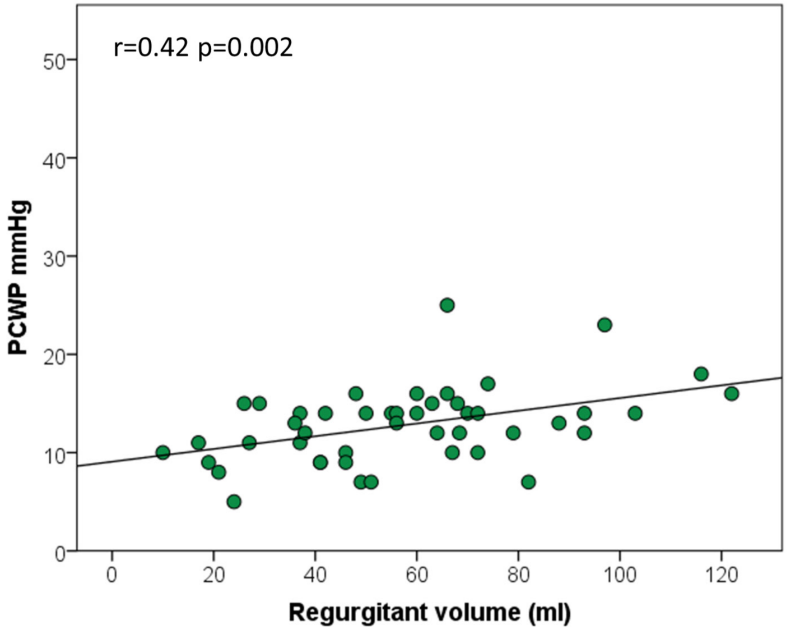

Regurgitant volume was also closely associated with severity of LA dilatation, but not LA function, where both LA active emptying and fractional change were preserved despite severe MR. LA enlargement is a hallmark of severe $\mathrm{MR},{ }^{2}{ }^{4}$ where it can be conceptualised

\section{B Peak exercise}

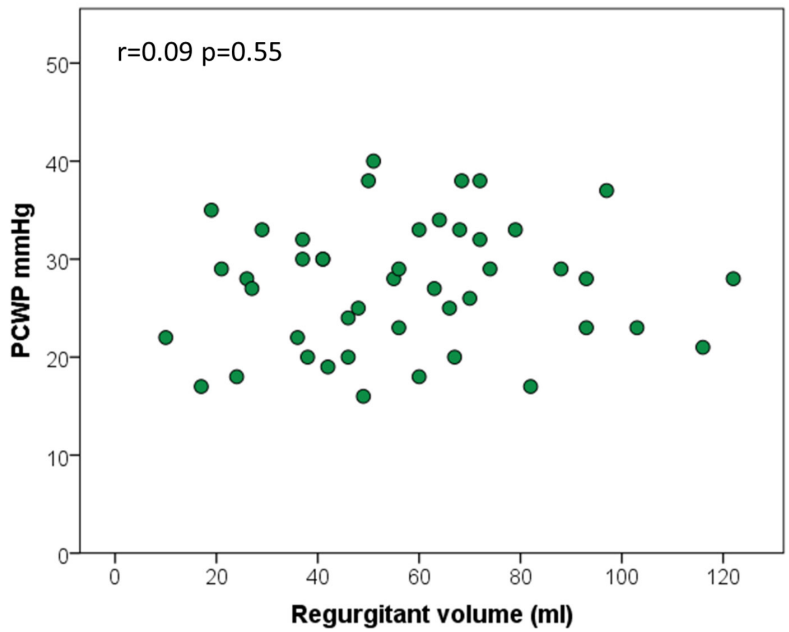

Figure 1 Scatterplot demonstrating a good association between regurgitant volume assessed on cardiac MRI and pulmonary capillary wedge pressure (PCWP) at rest (A) but not with exercise (B). 
A Rest

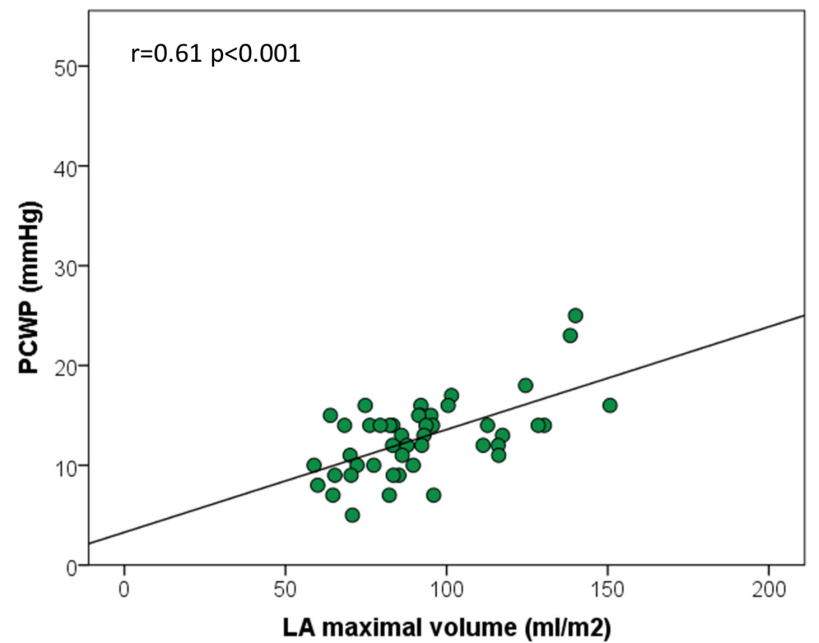

B Peak exercise

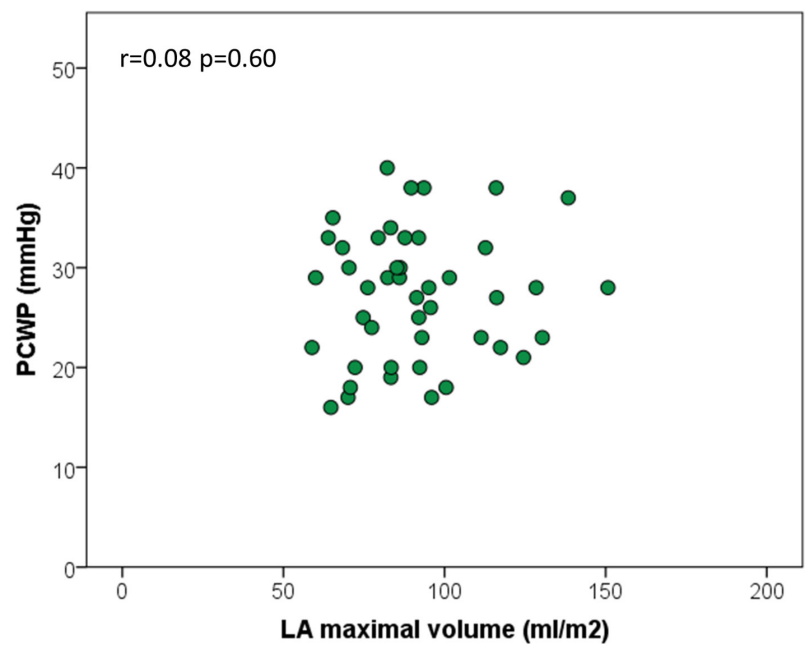

Figure 2 Scatterplot demonstrating a good association between left atrial (LA) maximal volume index assessed on cardiac $\mathrm{MRI}$ and pulmonary capillary wedge pressure (PCWP) at rest (A) but no association with exercise (B).

as an adaptive response to volume overload. Thus, LA dilatation will result in increased atrial compliance in an attempt to maintain normal LA (and pulmonary) pressures. In the present study we found extensive LA dilatation in all subjects. As expected LA size was associated with mitral regurgitant volume. In addition we also found at rest a good association between LA size (LA maximal, minimal and preatrial contraction volumes) and PCWP at rest. This demonstrates that LA volume in primary MR carries important information of the haemodynamic burden of the valve disease.

In patients with LV pressure overload such as severe aortic stenosis, ${ }^{20} 21$ patients with heart failure with preserved $\mathrm{EF}^{22}$ and patients with diastolic dysfunction after acute myocardial infarction, ${ }^{23}$ we and others have demonstrated that even if PCWP at rest is normal, exercise with increased $\mathrm{CO}$ induces a considerable and uniform increase in PCWP, thereby unmasking the severity of diastolic dysfunction with exercise. In line with this, LA maximal volume and non-invasive surrogates of

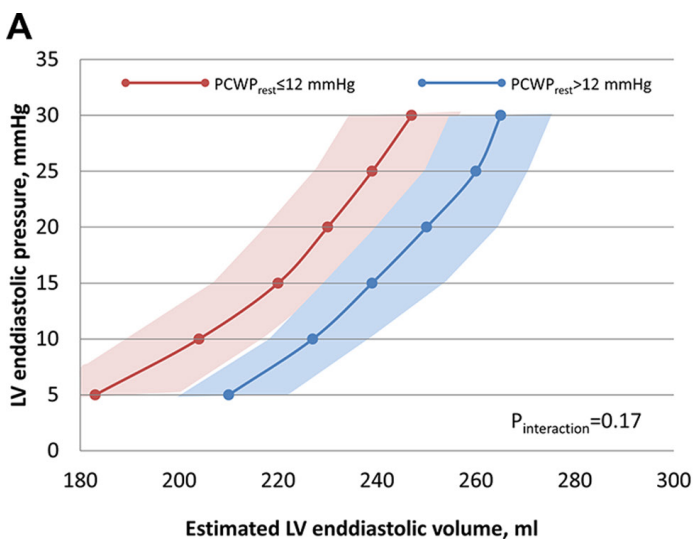

filling pressure on echocardiography have been shown to be associated with PCWP both at rest and with exercise in these conditions, where a severely enlarged LA will predict an abnormally increased PCWP with exercise. ${ }^{202123}$ Contrary to these disorders, we found no association between LA volumes or function with exercise PCWP in the volume-overload heart due to compensated significant MR. None of the associations detected at rest could be found with exercise. To further understand determinants of exercise PCWP we sought to determine EDPVR, which by definition indicates the amount of diastolic filling that will occur for a specified filling pressure and therefore is a key physiological determinant of preload. ${ }^{24}$ We adopted the method for estimating EDPVR from a single end-diastolic pressure-volume point which has been described and validated previously in detail. ${ }^{15} 16$ Doing this we found that patients with an increased PCWP at rest had a right-shifted EDPVR; thus, for a given EDPVR, LVEDV was increased suggesting a more compliant LV. This compares well with higher mitral regurgitant

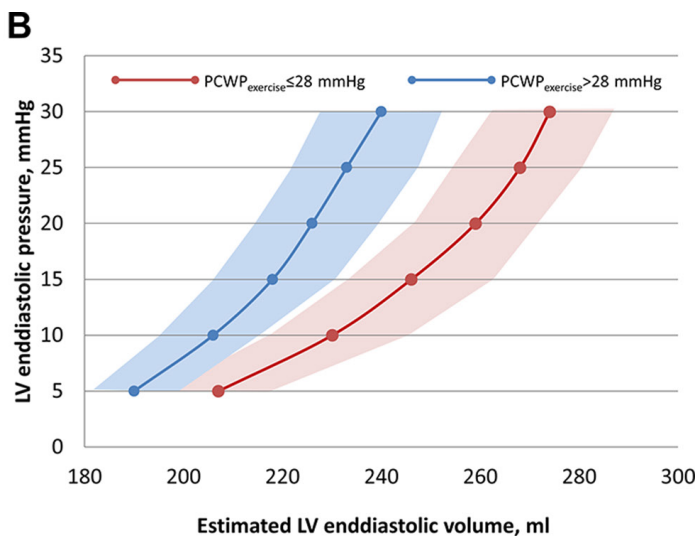

Figure 3 Single beat estimation of end-diastolic pressure volume relationship (EDPVR) in patients divided according to a normal pulmonary capillary wedge pressure (PCWP) $\leq 12 \mathrm{~mm} \mathrm{Hg}$ at rest (A) and a PCWP $\leq 28 \mathrm{~mm} \mathrm{Hg}$ with peak exercise (B). Patients with abnormal PCWP at rest had a right shift of EDPVR suggestive of a more compliant left ventricle (LV). This was the opposite in patients with increased PCWP with exercise where a left shift of EDPVR was seen suggestive of less compliance. 
volume in patients with increased resting PCWP; thus, the right shift of EDPVR signifies the expected adaption to volume overload in significant MR. However, patients, where exercise PCWP was abnormally increased, had a left shift of the resting EDPVR and a steeper slope than patients with normal PCWP with exercise, thus, adaption to significant MR could not be detected at rest based on conventional assessment of severity of chamber dilatation, severity of MR or resting PCWP. So where resting PCWP seems to reflect the severity of valve disease per se, exercise PCWP seems to a greater extent to reflect intrinsic diastolic LV function. Thus, people with exercise PCWP elevation display a physiology more like heart failure with preserved EF, and thus smaller, stiffer hearts and no plasma volume expansion. ${ }^{1722}$ This physiology was also associated with higher rate of referral for sugery even though the heart team was unaware of the result of catheterisation in most cases. Thus even though the number of patients is too low to draw any conclusion of therapeutic consequences, exercise haemodynamic assessment may provide additional information in the patient with ambiguous symptoms.

\section{Limitations}

All patients were required to undergo a cardiopulmonary exercise test and a significant number of patients declined participation, which may introduce selection bias by excluding more sedentary patients. Patients with pulmonary congestion or unstable haemodynamics were also excluded. Thus the present study only reflects ambulatory patients with significantly compensated MR.

A further limitation is that CMRI was done only at rest, thus we cannot measure the EDPVR during exercise. Previous data suggest an acute shift up and to the left of EDPVR in patients with heart failure and preserved $\mathrm{EF}^{25}$ Whether the EDPVR in patients with elevated exercise PCWP showed a further upward left shift of EDPVR is speculative. The subjects were examined with right heart catheterisation during semisupine exercise, and results may differ with exercise in the upright position, as venous return is increased in the semisupine position. We used a cut-off of $28 \mathrm{~mm} \mathrm{Hg}$ in PCWP for abnormal PCWP with exercise based on a previous study by Wolsk et al, ${ }^{14}$ which is higher than the often used threshold of $25 \mathrm{~mm} \mathrm{Hg}$. This was done to ensure the group with increased exercise PCWP truly were abnormal.

Measurement of aortic flow at the sinotubular junction (instead of at the level of the valve) might underestimate the aortic flow by $10 \%-15 \%{ }^{26}$ and thus cause modest overestimation of the regurgitant volume on CMRI. However, quantification of MR severity by CMRI is generally associated with high accuracy and reproducibility. ${ }^{5}{ }^{19}$ The relative small sample size increases the risk of statistical uncertainty but to our knowledge this is the first study to describe invasively measured haemodynamic characteristics and associations with LV and LA morphology obtained with CMRI in patients with significant MR.

\section{CONCLUSION}

In patients with significant primary MR, the degree of $\mathrm{LV}$ and especially LA dilatation is associated with resting PCWP, V-wave and PAP at rest. In contrast, exercise haemodynamics have little relationship to MR severity, and alterations in LV diastolic chamber compliance are the more important determinant. Estimation of EDPVR suggests lower LV compliance in patients with elevated PCWP with exercise, an association that was not seen for patients with increased resting PCWP, thus, suggesting that filling pressures with exercise are determined by intrinsic LV diastolic properties in primary MR, whereas resting haemodynamics are more closely associated with severity of MR.

Contributors Conception or design of the work: RB, JEM, BAB, MJA. Data collection: RB, AB, RP. Data analysis and interpretation: all authors. Drafting the article: JEM. Critical revision of the article: all authors. Final approval of the version to be published: all authors.

Funding The Danish Heart Foundation, Copenhagen; Region of Southern Denmark; University of Southern Denmark, Odense; The Consultants Council of research Foundation, Odense; and Werner Richter and Wife Foundation, Gentofte, Denmark.

Competing interests None declared.

Patient consent for publication Not required.

Ethics approval Ethical committee for Region of Southern Denmark (ID S-20140127).

Provenance and peer review Not commissioned; externally peer reviewed.

Data sharing statement No additional data are available.

Open access This is an open access article distributed in accordance with the Creative Commons Attribution Non Commercial (CC BY-NC 4.0) license, which permits others to distribute, remix, adapt, build upon this work non-commercially, and license their derivative works on different terms, provided the original work is properly cited, appropriate credit is given, any changes made indicated, and the use is non-commercial. See: http://creativecommons.org/licenses/by-nc/4.0

\section{REFERENCES}

1. Nkomo VT, Gardin JM, Skelton TN, et al. Burden of valvular heart diseases: a population-based study. Lancet 2006;368:1005-11.

2. Le Tourneau T, Messika-Zeitoun D, Russo A, et al. Impact of left atrial volume on clinical outcome in organic mitral regurgitation. J Am Coll Cardiol 2010;56:570-8.

3. Ling LH, Enriquez-Sarano M, Seward JB, et al. Clinical outcome of mitral regurgitation due to flail leaflet. $N$ Engl J Med 1996;335:1417-23.

4. Rusinaru D, Tribouilloy C, Grigioni F, et al. Left atrial size is a potent predictor of mortality in mitral regurgitation due to flail leaflets: results from a large international multicenter study. Circ Cardiovasc Imaging 2011;4:473-81.

5. Kramer CM, Barkhausen J, Flamm SD, et al. Standardized cardiovascular magnetic resonance imaging (CMR) protocols, society for cardiovascular magnetic resonance: board of trustees task force on standardized protocols. J Cardiovasc Magn Reson 2008;10:35.

6. Polte CL, Bech-Hanssen O, Johnsson $\AA$ A, et al. Mitral regurgitation quantification by cardiovascular magnetic resonance: a comparison of indirect quantification methods. Int $J$ Cardiovasc Imaging 2015;31:1223-31.

7. Myerson SG, d'Arcy J, Christiansen JP, et al. Determination of Clinical Outcome in Mitral Regurgitation With Cardiovascular Magnetic Resonance Quantification. Circulation 2016;133:2287-96.

8. Uretsky S, Gillam L, Lang R, et al. Discordance between echocardiography and MRI in the assessment of mitral regurgitation severity: a prospective multicenter trial. J Am Coll Cardiol 2015;65:1078-88.

9. Penicka M, Vecera J, Mirica DC, et al. Prognostic implications of magnetic resonance-derived quantification in asymptomatic patients with organic mitral regurgitation: comparison with doppler 
echocardiography-derived integrative approach. Circulation 2018;137:1349-60.

10. Bakkestrøm R, Banke A, Christensen NL, et al. Hemodynamic Characteristics in Significant Symptomatic and Asymptomatic Primary Mitral Valve Regurgitation at Rest and During Exercise. Circ Cardiovasc Imaging 2018;11:e007171.

11. Nishimura RA, Otto CM, Bonow RO, et al. 2014 AHA/ACC Guideline for the Management of Patients With Valvular Heart Disease: executive summary: a report of the American College of Cardiology/ American Heart Association Task Force on Practice Guidelines. Circulation 2014;129:2440-92.

12. Schulz-Menger J, Bluemke DA, Bremerich J, et al. Standardized image interpretation and post processing in cardiovascular magnetic resonance: Society for Cardiovascular Magnetic Resonance (SCMR) board of trustees task force on standardized post processing. $J$ Cardiovasc Magn Reson 2013;15:35.

13. Pichard AD, Kay R, Smith $\mathrm{H}$, et al. Large $\mathrm{V}$ waves in the pulmonary wedge pressure tracing in the absence of mitral regurgitation. $A m ~ J$ Cardiol 1982;50:1044-50.

14. Wolsk E, Bakkestrøm R, Thomsen JH, et al. The influence of age on hemodynamic parameters during rest and exercise in healthy individuals. JACC Heart Fail 2017;5:337-46.

15. Klotz S, Hay I, Dickstein ML, et al. Single-beat estimation of end-diastolic pressure-volume relationship: a novel method with potential for noninvasive application. Am J Physiol Heart Circ Physiol 2006;291:H403-H412.

16. Gayat E, Mor-Avi V, Weinert L, et al. Noninvasive estimation of left ventricular compliance using three-dimensional echocardiography. $J$ Am Soc Echocardiogr 2012;25:661-6.

17. Obokata M, Reddy YNV, Pislaru SV, et al. Evidence supporting the existence of a distinct obese phenotype of heart failure with preserved ejection fraction. Circulation 2017;136:6-19.
18. Reddy YNV, Melenovsky V, Redfield MM, et al. High-Output Heart Failure: A 15-Year Experience. J Am Coll Cardiol 2016;68:473-82.

19. Aplin M, Kyhl K, Bjerre J, et al. Cardiac remodelling and function with primary mitral valve insufficiency studied by magnetic resonance imaging. Eur Heart $J$ Cardiovasc Imaging 2016;17:863-70.

20. Christensen NL, Dahl JS, Carter-Storch R, et al. Association between left atrial dilatation and invasive hemodynamics at rest and during exercise in asymptomatic aortic stenosis. Circ Cardiovasc Imaging 2016;9.

21. Dalsgaard $M$, Kjaergaard J, Pecini R, et al. Left ventricular filling pressure estimation at rest and during exercise in patients with severe aortic valve stenosis: comparison of echocardiographic and invasive measurements. J Am Soc Echocardiogr 2009;22:343-9.

22. Borlaug BA, Nishimura RA, Sorajja P, et al. Exercise hemodynamics enhance diagnosis of early heart failure with preserved ejection fraction. Circ Heart Fail 2010;3:588-95.

23. Andersen MJ, Ersbøll M, Bro-Jeppesen J, et al. Exercise hemodynamics in patients with and without diastolic dysfunction and preserved ejection fraction after myocardial infarction. Circ Heart Fail 2012;5:444-51.

24. Zhang W, Kovács SJ. The diastatic pressure-volume relationship is not the same as the end-diastolic pressure-volume relationship. Am J Physiol Heart Circ Physiol 2008;294:H2750-60.

25. Borlaug BA, Jaber WA, Ommen SR, et al. Diastolic relaxation and compliance reserve during dynamic exercise in heart failure with preserved ejection fraction. Heart 2011;97:964-9.

26. Bertelsen L, Svendsen JH, Køber L, et al. Flow measurement at the aortic root - impact of location of through-plane phase contrast velocity mapping. J Cardiovasc Magn Reson 2016;18:55. 